\title{
Mapping of additive and epistatic QTLs linked to seed longevity in bread wheat (Triticum aestivum L.)
}

\author{
Mian Abdur Rehman Arif ${ }^{1}$ (D) Monika Agacka-Mołdoch ${ }^{2} \cdot$ Calvin O. Qualset $^{3} \cdot$ Andreas Börner $^{4}$
}

Received: 30 June 2021 / Accepted: 16 December 2021 / Published online: 11 January 2022

(c) The Author(s) 2022

\begin{abstract}
Plant genetic resources are stored and regenerated in $>1750$ gene banks storing $>7,000,000$ accessions. Since seeds are the primary storage units, research on seed longevity is of particular importance. Quantitative trait loci (QTL) analysis of 15 traits related to seed longevity and dormancy using 7584 high-quality SNPs recorded across 2 years and originated from five production years revealed a total of 46 additive QTLs. Exploration of the QTLs with epistatic effect resulted in the detection of 29 pairs of epistatic QTLs. To our information, this is only the second report of epistatic QTLs for seed longevity in bread wheat. We conclude that in addition to dense genetic maps, the epistatic interaction between loci should be considered to capture more variation which remained unnoticed in additive mapping.
\end{abstract}

Keywords Seed longevity $\cdot$ Seed dormancy $\cdot$ QTL mapping $\cdot$ Epistasis $\cdot$ SNP $\cdot$ Wheat

\section{Introduction}

To protect from extinction, plant genetic resources are stored and regenerated in $>1750$ gene banks storing $>7,000,000$ accessions (FAO 2010; Levin 2013) where major research areas include genetic integrity, diversity and seed longevity (Börner et al. 2012). A systematic evaluation of survival of the plant material at gene bank repositories is always underway (Rehman-Arif and Börner 2019). Since seeds are the prime storage material, research on seed longevity is of particular importance (Börner et al. 2012).

Genetic mapping of seed longevity was initiated at the beginning of last decade with the arrival of molecular markers (Rehman-Arif et al. 2012). In wheat, in fact, albeit few

Communicated by E. Khlestkina.

Mian Abdur Rehman Arif

m.a.rehman.arif@gmail.com

1 Nuclear Institute for Agriculture and Biology, Faisalabad, Pakistan

2 Institute of Soil Science and Plant Cultivation, State Research Institute, ul. Czartoryskich 8, 24-100 Puławy, Poland

3 Plant Sciences Department, University of California, Mail Stop 3, One Shields Avenue, Davis, CA 95616, USA

4 Leibniz Institute of Plant Genetics and Crop Plant Research, Gatersleben, Germany likely genes, dissimilar loci linked to germination after longterm cold storage $\left[\sim 35\right.$ years at $0 \pm 1{ }^{\circ} \mathrm{C}$ at $10 \pm 1 \%$ relative humidity (RH)] (Rehman-Arif et al. 2017) or medium-term cold storage (12-14 years at $10{ }^{\circ} \mathrm{C}$ and $50 \% \mathrm{RH}$ ) (AgackaMołdoch et al. 2016) in comparison with artificial ageing protocols were identified which implied that the induced ageing protocols do not reveal predictive behaviour of the deteriorative effect of long-term storage (Schwember and Bradford 2010).

Previously, we have shown that re-analysis of two association mapping panels from Rehman-Arif et al. (2012) and Rehman-Arif et al. (2017) using newly created SNP marker data resulted in the detection of 13 potential novel quantitative trait loci (QTLs) linked to seed longevity (Rehman-Arif and Börner 2020). Based on comparisons from Zuo et al. (2019) and Zuo et al. (2018), stem rust resistance protein Rpg1, NBS-LRR resistance-like protein and FARl-related sequence 6-like protein were identified as probable candidate genes for seed longevity in wheat.

In this report, we turn up to the re-analysis of a biparental mapping population known as "International Triticeae Mapping Initiative" (ITMI) which has been investigated regarding seed longevity after artificial ageing and dormancy by Rehman-Arif et al. (2012) as well as seed longevity after natural ageing by Agacka-Mołdoch et al. (2016). The concerned plant material is recently reported to be mapped with 7584 high-quality single-nucleotide polymorphism (SNP) 
markers that have yielded many novel loci for many diverse traits (Rehman-Arif et al. 2021). Hence, the objective of this study was to map new loci linked to seed longevity and dormancy based on the newly generated genotypic data reported in Rehman-Arif et al. (2021). In addition, epistasis QTLs and the connection between longevity and dormancy were explored. Finally, a possible alliance between longevity and dormancy was sought.

\section{Materials and methods}

\section{Materials}

A subset of 92 RILs from an "International Triticeae Mapping Initiative" (ITMI) population reported in Rehman Arif et al. (2021) was used in this study.

\section{Methods}

Phenotypic data published in Rehman-Arif et al. (2012) and Agacka-Mołdoch et al. (2016) were used. Data were gathered from different experiments performed with seeds from five different production years produced at two different locations (IPK-Gatersleben, Germany [years 2003 and 2009 referred to as set (i)] and Tulelake, CA, USA [years 2000, 2002 and 2013 referred to as set (ii)]. Seed longevity in set (i) was assessed by subjecting seeds to accelerated ageing (AA) and/or controlled deterioration (CD) tests [for details see Rehman-Arif et al. (2012)] and dormancy assessed by germinating seeds at 10 and $20^{\circ} \mathrm{C}$ from which dormancy index (DI) was calculated. Whereas set (i) experiments were performed in 2009, set (ii) seeds were assessed in 2014 through standard germination tests of fresh seeds produced in 2013 (IG_13) and seeds produced in 2000 and 2002 (GNA_00 and GNA_02, respectively). The number of seeds, replicates, storage conditions and abbreviations are provided in Table 1 .

\section{Genetic mapping}

Additive QTLs were detected using inclusive composite interval mapping (ICIM-ADD) command implemented in IciMapping 4.1 (http://www.isbreeding.net/), where the walking speed was kept $1.0 \mathrm{cM}$. On the lines of RehmanArif and Börner (2019) and Rehman-Arif et al. (2012), all QTLs $>1.5$ LOD and explaining $\geq 5 \%$ phenotypic variation (PVE) were reported. Digenic epistasis QTLs were identified using the ICIM-EPI command where LOD was kept $5.0 \mathrm{cM}$. Only, the epistasis QTLs with LOD $\geq 5$ and explaining $\geq 5 \%$ PVE were reported. All QTLs were assigned names according the rules set out in the Catalog of Gene Symbols (McIntosh et al. 2008). All additive and epistasis QTLs were visualized using "circlize" package in $\mathrm{R}$ ( $\mathrm{Gu}$ et al. 2014).

Table 1 Production year and location, storage conditions, year of experiments, traits measured, number of seeds and replicates and abbreviations of the set of grains analysed

\begin{tabular}{|c|c|c|c|c|c|}
\hline $\begin{array}{l}\text { Seeds produced (year } \\
\text { and location) }\end{array}$ & Storage conditions & $\begin{array}{l}\text { Experiments } \\
\text { performed } \\
\text { (year) }\end{array}$ & Traits measured & Abbreviations & $\begin{array}{l}\text { Number of seeds and } \\
\text { replicates }\end{array}$ \\
\hline 2000, Tulelake, CA & $\begin{array}{l}10 \pm 1{ }^{\circ} \mathrm{C} \text { and } 50 \pm 1 \% \\
\mathrm{RH}\end{array}$ & 2014 & Standard germination & GNA_00 & $\begin{array}{l}\text { Three replicates of } 50 \\
\text { seeds each }\end{array}$ \\
\hline 2002, Tulelake, CA & $\begin{array}{l}10 \pm 1{ }^{\circ} \mathrm{C} \text { and } 50 \pm 1 \% \\
\mathrm{RH}\end{array}$ & 2014 & Standard germination & GNA_02 & $\begin{array}{l}\text { Three replicates of } 50 \\
\text { seeds each }\end{array}$ \\
\hline 2003, IPK-Gatersleben & $\begin{array}{l}0 \pm 1^{\circ} \mathrm{C} \text { and } 10 \pm 1 \% \\
\mathrm{RH}\end{array}$ & 2009 & $\begin{array}{l}\text { Standard germination, } \\
\text { germination after AA, } \\
\text { relative germination } \\
\text { after AA }\end{array}$ & $\begin{array}{l}\text { IG_03, AA_03, } \\
\text { RAA_03 }\end{array}$ & $\begin{array}{l}\text { Four replicates of } 50 \\
\text { seeds each }\end{array}$ \\
\hline \multirow[t]{3}{*}{ 2009, IPK-Gatersleben } & - & 2009 & $\begin{array}{l}\text { Standard germination, } \\
\text { germination after AA, } \\
\text { relative germination } \\
\text { after AA }\end{array}$ & $\begin{array}{l}\text { IG_09, AA_09, } \\
\text { RAA_09 }\end{array}$ & $\begin{array}{l}\text { Four replicates of } 50 \\
\text { seeds each }\end{array}$ \\
\hline & & 2009 & $\begin{array}{l}\text { Standard germination, } \\
\text { germination after CD, } \\
\text { relative germination } \\
\text { after CD }\end{array}$ & $\begin{array}{l}\text { IG_09, CD_09, } \\
\text { RCD_09 }\end{array}$ & $\begin{array}{l}\text { Four replicates of } 50 \\
\text { seeds each }\end{array}$ \\
\hline & & 2009 & $\begin{array}{l}\text { Seed germination at } \\
10^{\circ} \mathrm{C} \text { and } 20^{\circ} \mathrm{C}\end{array}$ & D10, D20, DI & $\begin{array}{l}60 \text { seeds at } 10^{\circ} \mathrm{C} \text { and } 60 \\
\text { seeds at } 20^{\circ} \mathrm{C}\end{array}$ \\
\hline 2013, Tulelake, CA & $\begin{array}{l}10 \pm 1^{\circ} \mathrm{C} \text { and } 50 \pm 1 \% \\
\mathrm{RH}\end{array}$ & 2014 & $\begin{array}{l}\text { Standard germination } \\
\text { tests (GNA_00) }\end{array}$ & IG_13 & $\begin{array}{l}\text { Three replicates of } 50 \\
\text { seeds each }\end{array}$ \\
\hline
\end{tabular}




\section{Results}

\section{Phenotypic variation}

Phenotypic distributions of all the traits are provided in Fig. 1a-e. IG_03 was higher $(83.95 \pm 7.86)$ than IG_09 $(75.86 \pm 16.43)$ in spite of the fact that 2003 seeds were stored for six years at $0 \pm 1{ }^{\circ} \mathrm{C}$ and $10 \pm 1 \% \mathrm{RH}$. On the same pattern, AA_03 $(62.36 \pm 13.07)$ and RAA_03 $(74.07 \pm 12.94)$ were higher than corresponding AA_09 $(32.75 \pm 22.34)$ and RAA_09 $(40.61 \pm 24.37)$ values. Mean values of CD_09 and RCD_09 were 26.79 \pm 25.20 and $33.25 \pm 28.40$, respectively. There were more seeds dormant at $20{ }^{\circ} \mathrm{C}(76.10 \pm 26.88)$ than at $10{ }^{\circ} \mathrm{C}$ $(9.58 \pm 10.44)$ where the value of DI was $31.77 \pm 12.79$.
IG_13 $(96.94 \pm 1.85)$ was also higher than GNA_00 $(70.68 \pm 15.97)$ and GNA_02 (67.37 \pm 13.30$)$.

\section{QTL mapping}

QTL analysis of the 15 traits recorded across two years from five production years (Table 1) revealed a total of 46 additive QTLs where there were only six QTLs (linked to four traits viz. D20, DI, IG_13 and GNA_02) with LOD > 3 (Table S1) which explained up to $32 \%$ variation (D20) (Fig. 2). For IG_03, there were three QTLs on chromosomes 4A, 5A and 5B. The five QTLs of AA_03 were distributed on chromosomes $2 \mathrm{~B}, 4 \mathrm{~A}, 5 \mathrm{~B}, 6 \mathrm{~B}$ and $7 \mathrm{~B}$, whereas the two QTLs linked to RAA_03 were located on chromosomes 2B and 7A.

For IG_09, we detected five QTLs on chromosomes 2B, 4A, 5D, 6D and 7A. The three QTLs of AA_09 colocated with the three QTLs of RAA_09 on chromosomes 5A (2

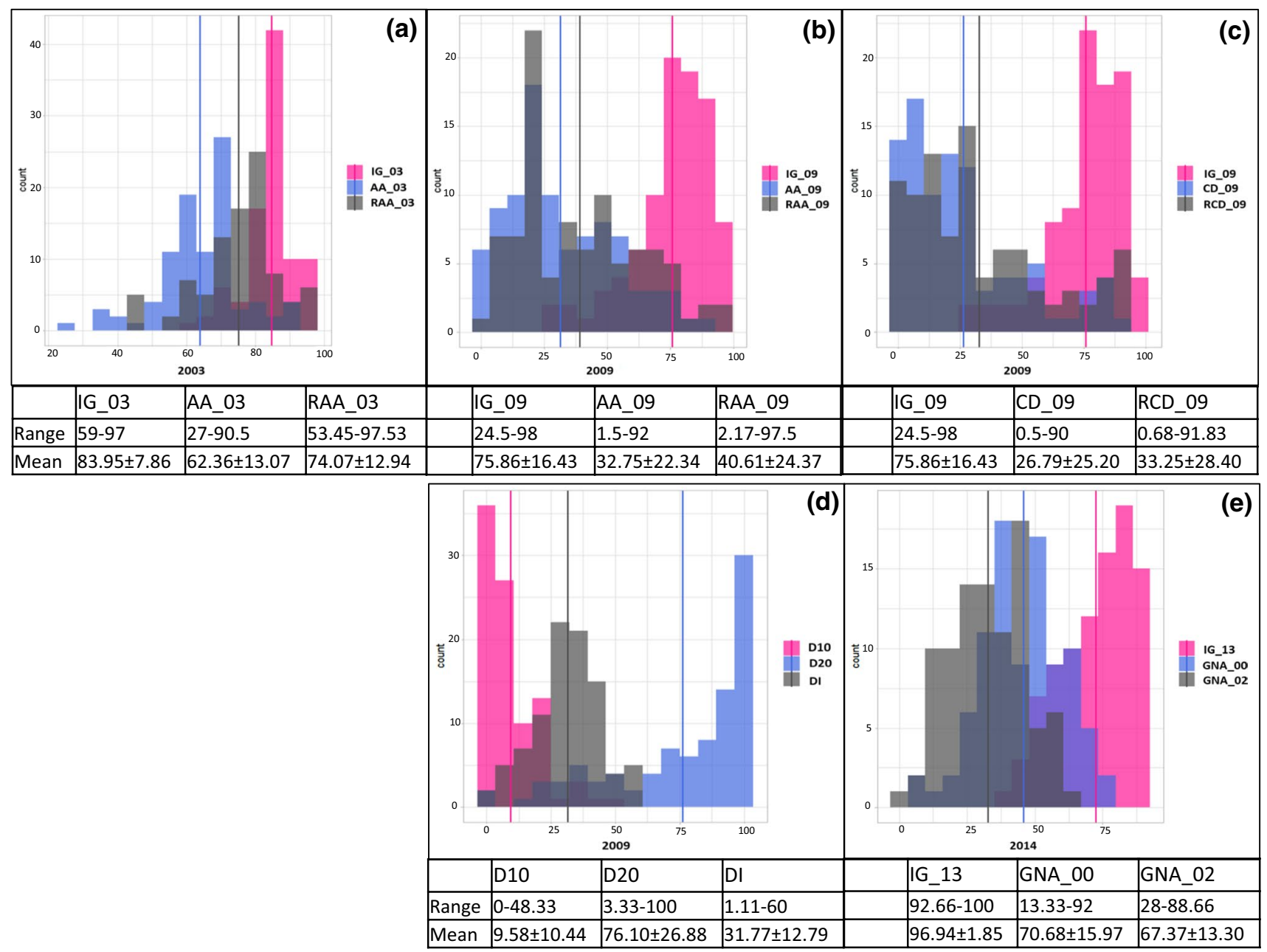

Fig. 1 Frequency distribution of a IG_03, GAA_03 and RAA_03, b IG_09, GAA_09 and RAA_09, c IG_09, GCD_09 and RCD_09, d D10, D20 and DI and e IG_13, GNA_00 and GNA_02 in various years. The $x$-axis shows the germination $\%$ in $\mathbf{a}, \mathbf{b}, \mathbf{c}$ and $\mathbf{e}$ and dor- mancy $\%$ in $\mathbf{d}$ and the $y$-axis shows the number of RILs (counts). The thick vertical lines indicate mean values of respective traits in each experiment. Tables below the graph indicate range and mean \pm SD of the traits 


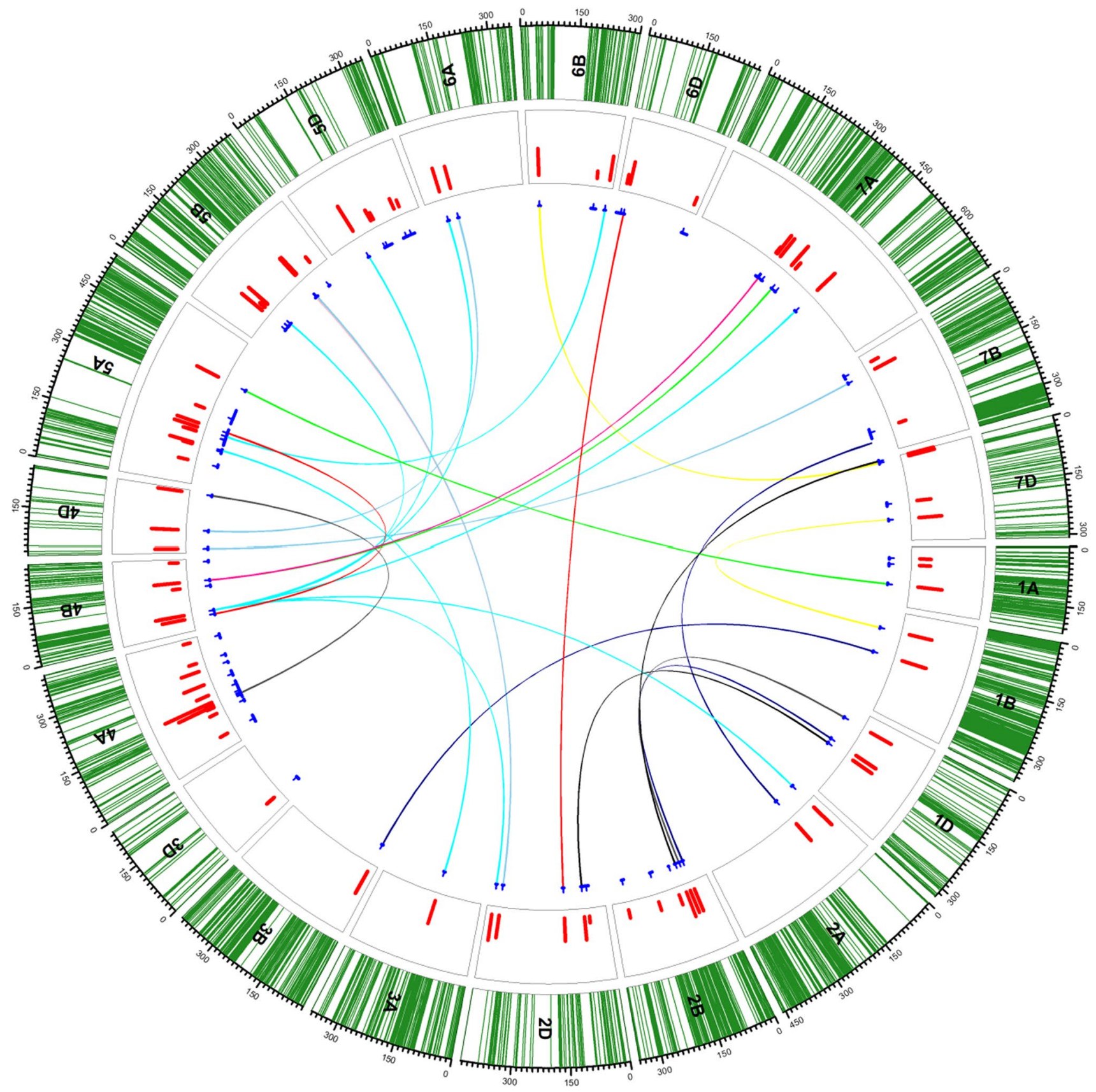

Fig. 2 Distribution of additive (unconnected blue lines in the inner circle) and epistatic (connected blue lines in inner circle) QTLs. Green lines in the outer track indicate the SNP positions on each chromosome; red bars in the second circle indicate the LOD values of QTLs. The blue lines under the track circle indicate the confidence interval of QTLs with small vertical lines point to the peak position of QTL. The coloured lines linked different biallelic epistasic QTLs $($ yellow $=$ IG_03; pink =AA_03; sky blue=RAA_03; navy blue $=$ AA_09,,$\quad$ aqua $=$ RCD_09; $\quad$ green $=$ D20; grey $=$ DI; black =GNA_00; deep pink $=$ GNA_02 and red=IG_13) (for reference, Tables S1 and S2). Coloured figure online

on chromosomes 4A and 5A. Two QTLs each were discovered for IG_13 (4A and 4B), GNA_00 (2B and 5B) and GNA_02 (3D and 4A).

Exploration of the QTLs with epistatic effect and QTL $\times$ environment interactions using QTL IciMapping 
resulted in the detection of 29 (58 QTLs in total) pairs of epistatic QTLs (Fig. 2, Table S2).

The two pairs of epistatic loci linked to IG_03 were detected on chromosomes 1B-7D and 6B-7D. Likewise, the two pairs of AA_03 epistatic QTLs were located on chromosomes 2D-5B and 4D-6A. Another three pairs linked to RAA_03 were located on chromosomes 2D-5B, 4D-6A and 4D-7B. Here the first two pairs were identical to AA_03 epistasis QTLs.

Of the seeds in 2009 production year, two pairs were linked to AA_09 on chromosomes 1B-3B and 1D-2B. Likewise, the first two pairs of RAA_09 epistasis QTLs overlapped exactly with AA_09 epistasis QTLs in addition to a pair on chromosomes 2A-7A. The maximum numbers of epistasis QTL pairs were detected for RCD_09 (eight pairs). Six of them involved one single locus on chromosome 4B that interacted with six other loci on chromosomes 2A, 2D, 5B, 5D, 6A and 7A. Furthermore, two other pairs were located on chromosomes $3 \mathrm{~A}-5 \mathrm{~A}$ and $5 \mathrm{~A}-6 \mathrm{~B}$. Two pairs of epistasis QTLs linked with D20 interacted on chromosomes 1A-5A and 4B-7A. Likewise, two pairs linked with DI interacted on chromosomes 1D-2B and 4A-4D.

With regard to IG_13, the two epistasis QTL pairs were located on chromosomes 2D-6D and 4B-5A. Another two pairs linked to GNA_00 were located on chromosomes 1D-2D and 2B-7D. Finally, the lone pair linked to GNA_02 was located on chromosomes 4B-7A.

\section{Discussion}

It has been shown that proper genome coverage is required to fully uncover the genetic makeup of any given character in a mapping population or germplasm collection (RehmanArif et al. 2021). An example with regard to seed longevity is the discovery of 13 potentially novel QTLs in two associations mapping panels (Rehman-Arif and Börner 2020). To add to it, most QTL mapping studies on seed longevity were focused on exploration of the additive effects of the genetic components in wheat (Agacka-Mołdoch et al. 2016, Rehman-Arif et al. 2012), barley (Nagel et al. 2009), rapeseed (Schatzki et al. 2013) and tobacco (Agacka-Mołdoch et al. 2015), whereas epistatic effects of the genetic components have not been addressed yet.

This study reports QTLs for series (i) seeds produced in 2003 on chromosomes 4A, 5A and 5B (IG_03), 2B, 4A, 5B, 6B and 7B (AA_03) and 2B and 7A (RAA_03). Common chromosomes to Rehman-Arif et al. (2012) and Agacka-Mołdoch et al. (2016) were 6B and 2B. Likewise, this study highlighted QTLs for series (i) seeds produced in 2009 on chromosomes 2B, 4A, 5D, 6D and 7A (IG_09), 5A and 5D (AA_09 and RAA_09), 5D (CD_09) and 1A, 5B, 5D and 7B (RCD_09). Here, the common chromosomes to
Rehman-Arif et al. (2012) and Agacka-Mołdoch et al. (2016) include 7A and 7B. D10 and D20 QTLs alongside the DI QTL on chromosome 5A remained unaddressed before. Thus, several new loci in particular on chromosomes $4 \mathrm{~A}$ and group 5 chromosomes (16 QTLs) linked to either seed longevity or dormancy were detected. It is pertinent to mention that Rehman-Arif et al. (2012) did not detect any QTLs on group 5 chromosomes, whereas only one QTL on chromosome 5D was detected by Agacka-Mołdoch et al. (2016) for AA_03. This could be attributed to the 1147 SNPs mapped to group 5 chromosomes which was otherwise scarcely covered hitherto (Rehman-Arif et al. 2021). Chromosomes $5 \mathrm{~A}$ and $5 \mathrm{~B}$ have been reported to be an important site for genes linked to plant survival (Rehman-Arif et al. 2020, Rehman-Arif and Börner 2019, Peleg et al. 2009). Furthermore, chromosome 5D has been reported to harbour several longevity loci according to Landjeva et al. (2010). In rice, chromosome 9 carried consistent seed longevity QTLs and synchronicity between group 5 chromosomes of wheat and chromosome 9 of rice with respect to longevity is already reported Rehman-Arif et al. (2017). The same conclusion is drawn in a barley study by Nagel et al. (2009).

Of the 32 sequences of SNPs involved in QTLs on group 4 and 5 chromosomes, 11 provided blast hits connected to various probable candidate genes involved in longevity and dormancy in bread wheat. For example, for a DI QTL on chromosome 4A, noroxomaritidine synthase (also known as CYP96T1) 2-like was identified. CYP96T1 is known to be involved in galanthamine metabolic pathway ( $\mathrm{Li}$ et al. 2020). However, its association with dormancy remained unknown. Another gene involved with DI was protein kinase G11A. In addition, aspargine synthetase was identified as candidate gene for DI, AA and RGAA on chromosome 5A. The bread wheat asparagine synthetase gene family is composed of five genes, viz. TaASN1, TaASN2, TaASN3.1, TaASN3.2 and TaASN4. Among them, TaASN1s are located on group 5 chromosomes and expressed during mid-development of grains (Raffan and Halford 2021).

For standard germination, on chromosome 4A, ankyrin (ANK)-3-like isoform X1 and $60 \mathrm{~S}$ ribosomal protein L10a and on chromosome 5A pentatricopeptide repeat-containing protein were identified. ANK proteins in plants play important roles in plant immunity, development and growth, and they are typically involved in protein-protein interactions (Kolodziej et al. 2021), whereas members of the pentatricopeptide repeat (PPR) protein family are sequence specific RNA binding proteins that play crucial roles in organelle RNA metabolism (Yan et al. 2019).

Likewise, for germination after natural ageing, geraniol 8-hydroxylase-like provided a blast hit on chromosome 4B. Geraniol 8-hydroxylase-like protein is known to be associated with MAP kinase signalling pathways (Figueiredo et al. 2018). In the end, the candidate genes associated 
with experimental ageing (AA/CD) included ETHYLENEINSENSITIVE 2-like (EIN2) and RDM16-like isoform X2 on chromosome 5A and carotenoid 9,10(9',10')-cleavage dioxygenase-like isoform $\mathrm{X} 1$ and aspartyl protease family protein 2-like on chromosome 5B. EIN2 controls miRNA164 expression that remains unchanged during ageing (Reinbothe et al. 2009). Similarly, carotenoid cleavage deoxygenases cleaved the carotenoids and apocarotenoids are produced by their action which are known to play various roles in the growth and development of plants (Ohmiya 2009) and members of aspartyl protease family are involved in regulating plant defence responses (Saibi et al. 2016).

We further conclude that in the ITMI/MP, seed longevity and dormancy are controlled differently just like in Arabidopsis (Nguyen et al. 2012), in spite of the fact that there were some common markers shared between dormancy and longevity, particularly on chromosome $5 \mathrm{~A}$ where the possible candidate genes involved were protein kinase G11A and aspargine synthetase whose exact role in these two phenomena remain elusive so far. This complexity could also be attributed to the hexaploid nature of bread wheat. Hence, much work remains to shed more light on the molecular mechanisms involved in dormancy and longevity in wheat.

We determined that in addition to additive loci, seed longevity is also controlled by epistatic loci. For example, we detected an additional 24.6, 20.9 and $44.3 \%$ variation in IG_03, AA_03 and RAA_03, respectively, in set (i) seeds of 2003 contributed by digenic epistatic loci (Table S3 and Fig. 2). On the same grounds, $37.3,40.9$ and $41 \%$ additional variations were uncovered for AA_09, CD_09 and RCD_09, respectively, in set (i) seeds of 2009. Additionally, 53.6 and $38.8 \%$ variation could be explained for D20 and DI. For set (ii) seeds, 16.8, 33.4 and 21.4 variations could be explained, respectively, for IG_13, GNA_00 and GNA_02. Previous studies using biparental populations and/or association mapping panels have reported additive QTLs only (Rehman-Arif and Börner 2020, 2019, Nagel et al. 2015, Agacka-Mołdoch et al. 2015, Schatzki et al. 2013, Rehman-Arif et al. 2012), but information on epistatic QTLs is just starting to be addressed in wheat (Shi et al. 2020) and tobacco (AgackaMołdoch et al. 2021). This report is only the second after Shi et al. (2020) to identify epistatic QTLs for seed longevity in bread wheat. A similar level of interactions has recently been detected for Karnal bunt in wheat in an association mapping panel by Singh et al. (2020). Full understanding of the impact of epistasis on quantitative traits, nevertheless, remains challenging (Le Rouzic and Álvarez-Castro 2008). Yet, on the basis of conclusion of the increased selection gain via marker-assisted breeding towards wheat yield (Reif et al. 2011) loci linked with seed longevity should be searched keeping in view the epistasis that might explain hidden variations of quantitative traits.
Supplementary Information The online version contains supplementary material available at https://doi.org/10.1007/s42976-021-00240-3.

Acknowledgements Mian Abdur Rehman Arif would like to thank Ziliang Luo, Agronomy Department, University of Florida, Gainesville, FL, USA, for helping with the codes of "circlize" package

Author's contribution MAR Arif and A Börner conceived the idea. MAR Arif, M Agacka-Mołdoch and CO Qualset performed the original experiments and provided the data sets. MAR Arif performed the analysis, carried out the visualization and wrote the manuscript. A Börner reviewed the manuscript. All authors read and approve the final manuscript.

\section{Declarations}

Conflict of interest The authors declare that they have no conflict of interest.

Ethical approval This article does not contain any studies with animals or humans performed by any of the authors.

Open Access This article is licensed under a Creative Commons Attribution 4.0 International License, which permits use, sharing, adaptation, distribution and reproduction in any medium or format, as long as you give appropriate credit to the original author(s) and the source, provide a link to the Creative Commons licence, and indicate if changes were made. The images or other third party material in this article are included in the article's Creative Commons licence, unless indicated otherwise in a credit line to the material. If material is not included in the article's Creative Commons licence and your intended use is not permitted by statutory regulation or exceeds the permitted use, you will need to obtain permission directly from the copyright holder. To view a copy of this licence, visit http://creativecommons.org/licenses/by/4.0/.

\section{References}

Agacka M, Nagel M, Doroszewska T, Lewis RS, Börner A (2015) Mapping quantitative trait loci determining seed longevity in tobacco (Nicotiana tabacum L.). Euphytica 202:479-486

Agacka M, Rehman Arif MA, Lohwasser U, Doroszewska T, Qualset CO, Börner A (2016) The inheritance of wheat grain longevity: a comparison between induced and natural ageing. J Appl Genet 57:477-481

Agacka M, Rehman Arif MA, Lohwasser U, Doroszewska T, Lewis RS, Börner A (2021) QTL analysis of seed germination related traits in tobacco (Nicotiana tabacum L.). J Appl Genet 62:441-444

Börner A, Khlestkina EK, Chebotar S, Nagel M, Rehman-Arif MA, Neumann K, Kobiljski B, Lohwasser U, Röder MS (2012) Molecular markers in management of ex situ PGR - a case study. J Biosci 37:871-877

FAO (2010) The second report on the state of the world's plant genetic resources for food and agriculture. Commission on Genetic Resources for Food and Agriculture, Food and Agriculture Organization of the United Nations, Rome, p 399

Figueiredo J, Silva SM, Figueiredo A (2018) Subtilisin-like proteases in plant defence: the past, the present and beyond. Mol Plant Pathol 19:1017-1028 
Gu Z, Gu L, Eils R, Schlesner M, Brors B (2014) Circlize implements and enhances circular visualization in R. Bioinformatics 30:2811-2812

Kolodziej MC, Singla J, Sánchez-Martín J, Zbinden H, Šimková H, Karafiátová M, Doležel J, Gronnier J, Poretti M, Glauser G (2021) A membrane-bound ankyrin repeat protein confers race-specific leaf rust disease resistance in wheat. Nat Commun 12:1-12

Landjeva S, Lohwasser U, Börner A (2010) Genetic mapping within the wheat D genome reveals QTL for germination, seed vigour and longevity, and early seedling growth. Euphytica 171:129-143

Le Rouzic A, Álvarez-castro JM (2008) Estimation of genetic effects and genotype-phenotype maps. Evol Bioinform 4:EBO S756

Levin SA (2013) Encyclopedia of biodiversity. Elsevier Inc

Li Q, Xu J, Yang L, Zhou X, Cai Y, Zhang Y (2020) Transcriptome analysis of gifferent tissues reveals key genes associated with galanthamine biosynthesis in Lycoris longituba. Front Plant Sci 11:1444

McIntosh R, Yamazaki Y, Dubcovsky J, Rogers W, Morris C, Sommers D (2008) Catalogue of gene symbols for wheat: 2008. In: Appels R, Eastwood R, Lagudah E, Langridge P, Mackay M, McIntyre L, et al (eds.), Proceedings of the 11th international wheat genetics. Sydney University Press, Sydney

Nagel M, Vogel H, Landjeva S, Buck-Sorlin G, Lohwasser U, Scholz U, Börner A (2009) Seed conservation in ex situ genebanks-genetic studies on longevity in barley. Euphytica 170:5-14

Nagel M, Kranner I, Neumann K, Rolletschek H, Seal CE, Colville L, Fernández-Marín B, Börner A (2015) Genome-wide association mapping and biochemical markers reveal that seed ageing and longevity are intricately affected by genetic background and developmental and environmental conditions in barley. Plant Cell Environ 38:1011-1022

Nguyen TP, Keizer P, van Eeuwijk F, Smeekens S, Bentsink L (2012) Natural variation for seed longevity and seed dormancy are negatively correlated in Arabidopsis. Plant Physiol 60(4): 2083-2092

Ohmiya A (2009) Carotenoid cleavage dioxygenases and their apocarotenoid products in plants. Plant Biotechnol 26:351-358

Peleg Z, Fahima T, Krugman T, Abbo S, Yakir D, Korol AB, Saranga Y (2009) Genomic dissection of drought resistance in durum wheat $\times$ wild emmer wheat recombinant inbreed line population. Plant Cell Environ 32:758-779

Raffan S, Halford NG (2021) Cereal asparagine synthetase genes. Ann Appl Biol 178:6-22

Rehman Arif MA, Börner A (2019) Mapping of QTL associated with seed longevity in durum wheat (Triticum durum Desf.). J Appl Genet 60:33-36

Rehman Arif MA, Börner A (2020) An SNP based GWAS analysis of seed longevity in wheat. Cereal Res Commun 48:149-156

Rehman Arif MA, Nagel M, Neumann K, Kobiljski B, Lohwasser U, Börner A (2012) Genetic studies of seed longevity in hexaploid wheat exploiting segregation and association mapping approaches. Euphytica 186:1-13
Rehman Arif MA, Nagel M, Lohwasser U, Börner A (2017) Genetic architecture of seed longevity in bread wheat (Triticum aestivum L.). J Biosci 42:81-89

RehmanArif MA, Attaria F, Shokat S, Akram A, Waheed MQ, Arif A, Börner A (2020) Mapping of QTLs associated with yield and yield related traits in durum wheat (Triticum durum Desf.) under irrigated and drought conditions. Int J Mol Sci 21:2372

RehmanArif MA, Shokat S, Plieske J, Ganal MW, Lohwasser U, Chesnokov YV, Nataliya V, Kocherina NV, Kulwal P, Kumar N, McGuire P, Sorrells ME, Qualset CO, Börner A (2021) A SNPbased genetic dissection of versatile traits in bread wheat (Triticum aestivum L.). Plant J 108:960-976. https://doi.org/10.1111/Tpj. 15407

Reif JC, Maurer HP, Korzun V, Ebmeyer E, Miedaner T, Würschum T (2011) Mapping QTLs with main and epistatic effects underlying grain yield and heading time in soft winter wheat. Theor Appl Genet 123:283-292

Reinbothe C, Springer A, Samol I, Reinbothe S (2009) Plant oxylipins: role of jasmonic acid during programmed cell death, defence and leaf senescence. FEBS J 276:4666-4681

Saibi W, Zouari N, Masmoudi K, Brini F (2016) Role of the durum wheat dehydrin in the function of proteases conferring salinity tolerance in Arabidopsis thaliana transgenic lines. Int J Biol Macromol 85:311-316

Schatzki J, Allam M, Klöppel C, Nagel M, Börner A, Möllers C (2013) Genetic variation for secondary seed dormancy and seed longevity in a set of black-seeded $\mathrm{E}$ uropean winter oilseed rape cultivars. Plant Breed 132:174-179

Schwember RA, Bradford KJ (2010) Quantitative trait loci associated with longevity of lettuce seeds under conventional and controlled deterioration storage conditions. J Exp Bot 61:4423-4436

Shi H, Guan W, Shi Y, Wang S, Fan H, Yang J, Chen W, Zhang W, Sun D, Jing R (2020) QTL mapping and candidate gene analysis of seed vigor-related traits during artificial aging in wheat (Triticum aestivum). Sci Rep 10:22060

Singh S, Sehgal D, Kumar S, Rehman-Arif MA, Vikram P, Sansaloni CP, Fuentes Dávila G, Ortiz C (2020) GWAS revealed a novel resistance locus on chromosome 4D for the quarantine disease Karnal bunt in diverse wheat pre-breeding germplasm. Sci Rep 10:1-11

Yan J, Yao Y, Hong S, Yang Y, Shen C, Zhang Q, Zhang D, Zou T, Yin P (2019) Delineation of pentatricopeptide repeat codes for target RNA prediction. Nucleic Acids Res 47:3728-3738

Zuo J, Liu J, Gao F, Yin G, Wang Z, Chen F, Li X, Xu J, Chen T, Li L, Li Y (2018) Genome-wide linkage mapping reveals qtls for seed vigor-related traits under artificial aging in common wheat (Triticum aestivum). Front Plant Sci 9:1101

Zuo JH, Chen FY, Li XY, Xia XC, Cao H, Liu JD, Liu YX (2019) Genome-wide association study reveals loci associated with seed longevity in common wheat (Triticum aestivum L.). Plant Breed 139:295-303 